\title{
EL PROYECTO MODERNIZADOR EN ARGENTINA Y BRASIL EN LOS AÑOS CINCUENTA. UN ESTUDIO COMPARADO*
}

\author{
Ana Inés López-Accotto y Alfredo A. Gugliano**
}

\section{PRESENTACION}

Nuestra propuesta es comparar las políticas económicas en Argentina y Brasil durante las gestiones de los Presidentes Arturo Frondizi (1958-1962) y Juscelino Kubitscheck de Oliveira (1956-1961), desde una triple perspectiva: desde la sociología histórica (reconstruyendo los procesos a los que se hace referencia y procurando contextualizarlos históricamente); desde la sociología política (centrándonos en las estrategias económicas de cada gobierno) ; y desde la sociología comparada (al tomar en consideración dos casos nacionales).

Quizás el esfuerzo sirva para replantearse si muchas de las cuestiones que hoy son presentadas como "novedosas" (globalización de la economía, papel del Estado y del mercado, problemas de la construcción de regímenes democráti$\cos$ ), no lo son tanto; indagar sobre las formas en que fueron planteadas en otros momentos; $y$, sobre todo, reflexionar sobre las soluciones que se ensayaron, por aquello de que "un pueblo que no conoce su historia está condenado a repetirla".

Como premisa de nuestro enfoque y siguiendo a Tilly (1992), es posible sostener que mientras que en Europa los Estados fueron el producto de largos, complejos y variados procesos de luchas y negociaciones, es decir, una resultante; en los países periféricos constituyen un requisito ex ante para poder incorporarse al sistema internacional, ya establecido como sistema interestatal. Esto no quiere decir que en el interior de cada uno de ellos no se produzcan también procesos complejos y variados de luchas y negociaciones, pero en un marco ya predefinido: el Estado nacional como actor internacionalmente válido.

Lo que parece relevante es que "los Estados nacionales aparecen siempre rivalizando entre sí y logran su identidad por contraste con Estados contrincantes; pertenecen a un sistema de Estados" (Tilly, 1990), en el que las interrelaciones no son banales ni constituyen aspectos secundarios en la

* Este articulo es una sintesis de la ponencia "Modernización, democracia y crisis política. Argentina y Brasil en los años cincuenta", presentada por los autores en el Congreso Español de Sociologia, Granada, sept. de 1995

** A. I. López-Accotto es investigadora de Sociologia Politica, adscrita al departamento de Sociologia I (Cambio Social), Univ. Complutense de Madrid. A.A. Gugliano es Licenciado en Historia por la Universidade Federal do Rio Grande do Sul y Doctorando en Sociologia en la Univ. Complutense de Madrid. propia existencia de cada uno de ellos. Se hallan insertos en un sistema de interrelaciones, en el que se establecen límites y posibilidades (o frenos y oportunidades) de actuación.

Durante los años cincuenta y sesenta se tendió a obviar esta multiplicidad de procesos y a creer en la existencia de un tipo ideal de formación del Estado y también del desarrollo económico a través de etapas acumulativas: la supuesta experiencia de los Estados nacionales de los países desarrollados constituían el paradigma. La modernización, en este sentido, consistía en seguir el mismo camino y pasar de sociedades tradicionales a sociedades modernas, en un tiempo más o menos rápido y aprendiendo a contener y gestionar los conflictos. Como en la época señalaba Talcott Parsons, los paises subdesarrollados poseían la ventaja de tener al modelo norteamericano como guía.

En el escenario internacional de posguerra, el debate sobre la modernización se planteaba entre los que defendían que el Estado debía ser el motor principal del proceso y los que consideraban que ese papel correspondía fundamentalmente al mercado. Bajo la influencia del pensamiento de Schumpeter se cuestionó la política de intervención del Estado en la economía como motor del desarrollo económico, que fuera dominante en la posguerra a través del pensamiento de Maynard Keynes.

En torno a 1955 las tendencias de la política económica cambiaron: con la llegada de los republicanos al gobierno en Estados Unidos en 1953, se fue imponiendo la tesis sobre el carácter innovador de las grandes empresas y monopolios en el desarrollo económico. Si bien no se produce un reconocimiento legal del monopolio, al menos se da un reconocimiento político, alegándose que la atomización de la actividad industrial puede ser causa de debilitamiento del poder económico y político internacional de la nación.

El debate sobre el papel del Estado estaba servido: la idea de la intervención en la economía que había tenido vigencia para todos los países de organización capitalista, desarrollados o subdesarrollados, durante las últimas décadas y la influencia del pensamiento keynesiano, comenzaban a ser cuestionados a principios de los años cincuenta, de la mano de los economistas neoliberales.

En el caso del proceso de modernización que se intentó implementar en varios países de América Latina, entre los años cincuenta y sesenta, este debate sobre el fortalecimien- 
to del Estado como un núcleo de dinamización de la economía constituyó un aspecto esencial. En realidad podríamos afirmar que aquí intentamos analizar un fenómeno simultáneo: si al paso que aumenta (o se debilita) el poder del Estado sobre las relaciones económicas, éste se fortalece como un instrumento de vertebración nacional.

Consideramos que los dos gobiernos que nos proponemos analizar son especialmente significativos porque tienen lugar en el contexto de este debate internacional y constituyeron dos formas distintas de responder al mismo. La comparación posibilita la reflexión en torno a estrategias diversas y la contrastación de sus resultados.

De una forma general el trabajo está planteado en dos partes: en la primera se trata de ver cómo se construye la idea latinoamericana de la modernidad a través de la contribución de la CEPAL.

En la segunda parte del trabajo entraremos en la comparación entre los gobiernos de Frondizi y Kubitschek. Después de analizar los antecedentes del periodo que investigamos, pasaremos a la cuestión de las estrategias económicas aplicadas por los referidos gobiernos y sus consecuencias.

Para finalizar, pretendemos enfatizar la actualidad de los estudios respecto a los intentos de modernización ocurridos entre los años cincuenta y sesenta, pues en realidad muchos de los problemas que se presentaron a las gestiones de Frondizi y Kubitschek se mantienen vivos, y, quizás, de sus errores y aciertos pudiéramos aprovechar algunos elementos para minimizar los efectos negativos de los actuales procesos de reforma económica en América Latina.

\section{LAS PROPUESTAS MODERNIZADORAS DE LA CEPAL}

Como es sabido, la CEPAL es una de las tres comisiones económicas regionales establecidas en el año 1947 por el Consejo Económico y Social de las Naciones Unidas y su sede fue establecida en Santiago de Chile. Puede decirse que la motivación central de las reflexiones del pensamiento cepalino fue la convicción de que la industrialización era una exigencia ineludible del desarrollo. De lo que se trataba era de entender las características específicas con que ésta se presentaba en América Latina, sus dificultades concretas y las posibles líneas de acción para su realización plena. En este esfuerzo se desarrollaron dos instrumentos conceptuales que tendrían gran impacto en la región: la teoría del sistema centro-periferia y las tesis sobre el proceso de industrialización latinoamericano.

Respecto al sistema centro-periferia, la idea nuclear de esta concepción es que el desarrollo económico, entendido como una acumulación de capital generada principalmente por el progreso tecnológico que posibilita un aumento de la productividad y mejoría del nivel de vida, asume características diferenciadas según la posición ocupada por las economías nacionales y/o regionales en el sistema mundial. Se sostiene la existencia de un desarrollo desigual originario entre los "centros" donde se despliegan primero las técnicas capitalistas de producción, por un lado, y las zonas que incorporan estas técnicas más tardíamente (la "periferia"), por otro.

Como consecuencia de esta desigualdad originaria, las relaciones de intercambio que se establecen entre ambos polos no sólo son también desiguales sino que, en virtud de la dinámica establecida, tienden a deteriorarse progresivamente, ahondándose las diferencias. Sin embargo, se sostiene, que llegado a un cierto grado de desarrollo del sistema mundial, cuando los dos polos alcanzan determinados niveles de productividad e ingresos medios, el juego de las fuerzas económicas impulsa espontáneamente la expansión de la industria en la periferia, lo que constituye "una etapa más en el fenómeno de propagación universal de las nuevas formas de la técnica productiva, o si se quiere, en el proceso de desarrollo orgánico de la economía del mundo" (Prebisch, 1949).

Esta fase de industrialización -que librada a su propia espontaneidad no haría más que reproducir las diferencias estructurales respecto al centro-, podía constituir, sin embargo, una oportunidad para romper el círculo vicioso entre ambos polos y modificar las dinámicas de relación existentes, si se procedía a una conducción deliberada del proceso de industrialización sustitutiva por medio de la planificación y de un papel muy activo por parte del Estado. Se considera que la burguesia industrial nacional es la que debe liderar este proceso, redefiniendo su participación en las relaciones sociales de forma acorde con sus propios intereses. El Estado debe promover y tutelar los cambios que se ocasionen en los distintos grupos sociales y arbitrar en los conflictos que ellos puedan suscitar.

De ahí la importancia estratégica que para estos economistas tenía el análisis y la elaboración de propuestas en torno al proceso de industrialización así como de una planificación que posibilitase el uso por parte del Estado de la variada panoplia de instrumentos que los estudios económicos podian ofrecerle. A ello dedicaron considerables esfuerzos durante los años cincuenta y sesenta.

De acuerdo con la CEPAL, el proceso de industrialización latinoamericano puede ser dividido en relación a la crisis de los años treinta, en dos épocas claramente diferenciadas, en virtud de la consideración de que esta crisis no fue simplemente una cuestión de coyuntura, sino que expresaba transformaciones profundas en las relaciones económicas internacionales: cambio de liderazgo, de Gran Bretaña a Estados Unidos; crisis del patrón oro como regulador del comercio; políticas proteccionistas y restricción del mercado internacional.

Mientras en el período anterior a 1930 el desarrollo de la industrialización estaba restringido a las necesidades y oportunidades generadas por el comercio internacional, (constituyendo una "industria de manufacturados auxiliares", como la describe la CEPAL), a partir de entonces nació la necesidad de una producción ampliada de manufacturas $o$, en un lenguaje más conocido, la sustitución de importaciones, para suplir la retracción del comercio internacional.

Las ideas de CEPAL se propagaron en forma despareja en los distintos países de América Latina: en una primera etapa, el ritmo de su difusión así como las actividades de investigación y las propuestas políticas a que dieron lugar, 
dependieron tanto de las personas concretas que las desarrollaron como de las circunstancias políticas de cada país y las características específicas de los gobiernos existentes. Las formas en que se produjo la expansión de las ideas y trabajos de la CEPAL y las repercusiones que ello tuvo en cada país, no fueron ajenas a la participación política de los técnicos vinculados a ella ni a la plasmación institucional de cooperación que tuvo lugar.

En Argentina (como en México) la CEPAL aparecía asociada a la controvertida figura de Prebisch. Desde el gobierno peronista Prebisch era presentado a la opinión pública como un "hombre de la oligarquía", ligándolo a los capitales ingleses y a algunos de los escándalos políticoeconómicos de los años treinta (Furtado, 1985). Su participación como asesor económico del gobierno militar que derrocará a Perón en 1955 y como autor del primer programa de estabilización para el país (similar a otros impulsados por el FMI en la región) no mejoraría en nada la opinión que sobre él tenían los sectores progresistas.

En lo que respecta a Brasil, la temprana incorporación de Celso Furtado, con una preocupación constante por la difusión de los trabajos de la CEPAL y la implicación de otros investigadores brasileños en los trabajos en curso, constituyeron factores claves para que este país (junto con Chile) fuera desde el principio uno de sus centros más dinámicos. El impulso dado desde el gobierno de Vargas a la formación, en 1953, de una comisión mixta de planificación del desarrollo brasileño integrada por técnicos de la CEPAL y del Banco Nacional de Desenvolvimento (BNDE), dirigida por Furtado, fue fundamental para el establecimiento de una cooperación muy activa.

Posteriormente, en un análisis crítico de sus propios postulados, los intelectuales de la CEPAL llegaron a la conclusión de que el proceso de industrialización en los años cincuenta-sesenta estuvo lejos de cumplir con las exigencias de la propia realidad de la región, por las siguientes razones:

a) La industrialización no reemplazó al sector externo como motor de la economía;

b) El aumento de la producción de manufacturas fue inferior al crecimiento de la población;

c) La participación del empleo industrial en el empleo total de la población es bajo si se compara con los países desarrollados;

d) La diversificación de la producción no se expandió hacia los productos intermedios;

e) El desarrollo industrial no contribuyó a la mejoría de la distribución del ingreso.

Como consecuencia de este fracaso en la implementación de los planes, que se manifestaba en la notoria disparidad entre los objetivos propuestos y las metas alcanzadas de hecho, sumado a la agudización creciente de los problemas sociales, en los años sesenta se produce en el seno de la CEPAL una relectura crítica de los propios postulados y una radicalización de algunos de los supuestos. En conjunto, lo que se manifiesta es un mayor énfasis en el intervencionismo del Estado y en la necesidad de planificación. Las propuestas orientadas a incidir en la estructura de la propiedad y en los aspectos sociales del desarrollo cobran mayor fuerza y visibilidad frente a una realidad que tendía a con- tradecir permanentemente sus planteamientos prospectivos de los años cincuenta.

La ausencia de una reflexión sistemática sobre los cambios acaecidos en las relaciones internacionales, fundamentalmente el inicio del proceso de descolonización inglés, el resurgimiento vigoroso de postulados neoliberales, la creciente integración de los mercados de los países centrales y la importancia del capital extranjero y de las empresas transnacionales en este proceso, señalaba los límites de la interpretación teórica de la CEPAL, sin que ello disminuyera el valor de sus aportaciones.

El modelo de desarrollo de la CEPAL, basado en una política industrialista de sustitución de importaciones, acabó generando un desarrollo económico apoyado en la concentración de la renta: se dejó de estimular la producción de bienes de consumo para los trabajadores y se pasó a privilegiar los bienes de consumo de los capitalistas. Más allá de esto, el Estado gradualmente redujo los beneficios sociales y pasó a invertir principalmente en la gran industria, asociada a importantes empresarios nacionales y extranjeros, lo que todavía empeoró más el problema de la desigualdad social.

Una cantidad ingente de literatura se dedicó a intentar explicar si el fracaso del paso de una etapa a otra de industrialización se debió a causas "endógenas" (la fragilidad de una burguesía industrial capaz de hegemonizar el proceso) o "exógenas" (la política expansiva del capitalismo monopolista y del "imperialismo").

Algunas críticas pusieron el acento sobre la falta de consideración en los análisis de la CEPAL sobre el papel jugado por la expansión de las empresas transnacionales y el capitalismo financiero. La temprana inserción de las economías periféricas en el mercado internacional, en calidad de agroexportadoras (en lo que se conoce como "crecimiento hacia afuera") habría determinado la consolidación de una burguesía oligárquica con fuertes lazos con las economías centrales. Esta modalidad de relación no habría sido transformada al comienzo del proceso de industrialización por sustitución de importaciones, sino que habría permanecido siempre: la presencia de capitales extranjeros, en sociedad con sectores de la burguesía local, que comenzó a través de empresas individuales en los años treinta y que a partir de la segunda mitad de los años cincuenta iría alcanzando niveles nacionales.

Autores como Sunkel, entre otros, indicaron que si bien los análisis centro-periferia reconocían la influencia del sistema capitalista global en los procesos de desarrollo de los países periféricos, no llegaron a reconocer el hecho de que todos forman parte de un mismo sistema y que no se trata de "influencias externas" sino de características constitutivas del sistema mismo.

Frente a la creciente integración a nivel mundial, podría hablarse de "interdependencia desigual", (Sunkel y Tomassini, 1984), recuperando la multidireccionalidad de las interrelaciones frente a planteamientos unidireccionalistas como los de la teoría de la dependencia, pero sin perder de vista el carácter desequilibrado o desigual de esas relaciones. Aún reconociéndose en la concepción centro-periferia las funciones que cumple esta última en el desarrollo de los países centrales, son los centros los que imponen el estilo, las dinámicas y los ritmos al sistema global y, en particular, 
a la periferia: "la interdependencia genérica tiene como base esos dos papeles sustancialmente diferenciados". (Pinto, 1979).

Los núcleos transnacionales existentes en el interior de los países periféricos juegan un papel muy activo en la formulación de las estrategias nacionales, buscando su adecuación al estilo de desarrollo hegemónico del sistema transnacionalizado (Sunkel y Tomassini,1984), que años después sería descrito como depredador y basado en la falsa creencia del crecimiento ilimitado (Primer informe del Club de Roma, Meadows y otros, 1972, por ejemplo).

El proceso es uno sólo, pero su dirección es doble: a medida que la integración de las economías periféricas en el sistema mundial se acrecienta y complejiza, las corporaciones transnacionales se "internalizan" en las economías periféricas, retroalimentándose mutuamente (Pinto, 1979).

Las dificultades crecientes a las que se iban enfrentando los países de la región en los años cincuenta, unidas a los cambios ideológicos que se estaban produciendo en el debate sobre economía en los países centrales y a la ausencia de un análisis crítico sobre el papel de las empresas transnacionales, llevaron al convencimiento, más o menos generalizado entre los responsables políticos y económicos de la época, acerca de la necesidad de recurrir a capitales extranjeros (bien como inversiones directas, bien vía préstamos de organismos internacionales) si se quería participar de esa promesa de crecimiento sin límites. Ello venía a coincidir con las nuevas tendencias expansivas de las grandes empresas de los paises centrales, en especial, las de origen norteamericano, y con las recomendaciones de los organismos financieros internacionales.

La progresiva recuperación de las tesis que privilegiaban al sector privado como motor central de la economía (en un momento en que se manifestaba una tendencia acelerada a la formación de conglomerados, con claras características oligopólicas), suscitó también críticas en torno no sólo a las deficiencias y límites de los análisis cepalinos de los años cincuenta, sino fundamentalmente a algunas plasmaciones políticas concretas, como la impulsada por Prebisch en Argentina a partir de 1955, que implicaban el abandono del papel dinámico del Estado en el proceso industrializador y su restricción a tareas de complemento o seguimiento de la actividad privada; y la apertura, prácticamente sin condiciones, a los capitales y empresas transnacionales.

El desarrollo de un cuerpo doctrinario común en la CEPAL tuvo repercusiones diversas en ambos países, en relación a características especificas de los procesos nacionales concretos: los análisis realizados no sólo se tradujeron en plasmaciones institucionales diferentes, sino que sirvieron de base y dieron cabida a propuestas políticas distintas para responder a los desafios de la década de los años cincuenta.

\section{ARGENTINA Y BRASIL A FINALES DE LOS AÑOS CINCUENTA}

El conjunto de los intentos de modernización en América Latina a partir de los años veinte fueron influidos, de una forma o de otra, por los dos grandes conflictos mundiales que ocurrieron entre 1914-1945, la I $\mathrm{I}^{\mathrm{a}}$ y la II $\mathrm{II}^{\mathrm{a}}$ Guerra Mundial, y sus implicaciones en la estructura de las sociedades contemporáneas.

La crisis económica de los años 30 es el punto de partida para comprender el proceso que llevaría a los intentos de cambio del modelo económico en general y, en concreto, en Argentina y Brasil. A partir de la crisis se entró en una fase de reducción progresiva de los precios de las exportaciones, concretamente de los productos agrarios, que eran la base de la producción latinoamericana. Además el conjunto de las grandes potencias mundiales de la época mantenían su atención política en el problema del pago de las indemnizaciones de guerra por parte de Alemania, sin mayores consideraciones sobre las consecuencias de este proceso en los países periféricos.

En este período Argentina y Brasil vivieron importantes procesos de cambio político. Uno de los puntos a destacar es que, a pesar de la coincidencia de fecha, los movimientos en ambos países tuvieron profundas diferencias e incluso se podría afirmar que fueron casi contradictorios. La propia forma en que estos movimientos fueron denominados son, en si mismas, muy sugerentes: en el caso argentino, los años 30 se conocen como la "década infame", algo que evidentemente no representa un elogio; en el caso brasileño se habla, en cambio, de la "revolución de 30", pues representa, por lo menos en el nombre, un proceso de ruptura con el orden establecido.

En Argentina, paradójicamente, la crisis internacional constituyó una oportunidad para los sectores tradicionales de recuperar posiciones frente a la relativa pérdida de control del aparato estatal que supusieron los gobiernos radicales, pues la extensión del sufragio y la organización de referentes políticos nuevos habian puesto en evidencia el carácter excluyente de la clase dominante. A partir del golpe militar encabezado por el general Uriburu, en 1930, se retomó el esquema que había hecho próspera a la nación en las décadas anteriores: una asociación muy estrecha con Gran Bretaña y su mercado.

En Brasil, donde la cuestión de la revolución de 30 hoy todavía es un punto de polémica, este proceso marcó el comienzo de una ruptura con las élites agroexportadoras. Sin duda ésta fue una extraña ruptura pues el propio Getúlio Vargas era un representante de las élites agrarias del sur del país; incluso hasta por lo menos 1937 , fecha que marca el comienzo del período dictatorial conocido como Estado Novo, el conjunto de la economía continuaba centrada en las exportaciones rurales. Sin embargo, a partir de 1930, independientemente de que caractericemos al movimiento como una verdadera revolución o no, la estructura política brasileña no volvió a ser como antes.

En una comparación con Argentina, se podría decir que los años treinta brasileños representaron un proceso mucho más decidido de cambio político y económico. Sin embargo, en términos de los śectores populares ésto quizás represente muy poca cosa, pues si es verdad que en Brasil no hubo un retroceso, ello se debe a que la estructura autoritaria implícita en el modelo de Estado oligárquico se había mantenido prácticamente intacta, sin avances democratizadores. 
El final de los años 30 fue marcado por el comienzo de la II ${ }^{\mathrm{a}}$ Guerra Mundial que se extendería hasta 1945. Cuando acaba este conflicto ambos países se enfrentaron al problema de profundizar el proceso de industrialización a través de la sustitución de importaciones y al dilema de cómo llevarlo a cabo.

En Argentina, en este periodo, hubo un cambio en la política económica por parte del gobierno Perón, -al que diversos sectores tildaron de totalitario, tanto en lo político como en el manejo de la economía- quien en los últimos años de su gobierno comenzó a asumir algunos de los postulados liberales de la época. No obstante lo cual fue derrocado. Con el golpe militar de 1955 y el nombramiento de Prebisch como asesor económico del gobierno se pasó a implementar una serie de medidas económicas, plasmadas en lo que se conoce como el "Informe Prebisch", que se proponian estimular la producción agropecuaria, desarticular las medidas intervencionistas y liquidar las empresas comerciales e industriales del Estado.

Estas medidas no lograron obtener los fines buscados y se produjo un fuerte aumento de precios seguido por un incremento de las importaciones como resultado de la ausencia de controles por parte del Estado. A principios de 1957 se produjo un cambio en el equipo económico del gobierno, en el intento de maximizar la racionalidad de la economía argentina a través de la plena vigencia de las leyes del mercado y el control sobre los salarios. Sin embargo en el transcurso de los dos años de gobierno militar el país perdió recursos en su comercio exterior así como comprometió gran parte de la renta nacional con el pago de créditos y permisos de importación. Este será el contexto de las elecciones generales de 1958 que llevaron a Arturo Frondizi a la presidencia de la nación.

En la historia política brasileña posterior a 1945 probablemente dos elementos pueden ser identificados como centrales. Uno se relaciona con el capital internacional y el otro con lo que llamaremos una obsesión por la intervención del Estado en la economía.

Respecto al capital extranjero, lo que podemos destacar es que en el período anterior a Kubitschek existió una gran expectativa en relación a un posible incremento de las inversiones norteamericanas en el país e incluso llegaron a constituirse comisiones de estudio, por ejemplo la Misión Abblink y la Comissao Mixta Brasil-Estados Unidos, que organizaron sendos informes sobre futuras inversiones norteamericanas en el país, que nunca fueron llevadas a cabo. Esto influyó en el cambio de actitudes en el período de Kubitschek.

Sobre la intervención obsesiva del Estado en la economía es necesario señalar que aún el más liberal de los presidentes del período, como fue Eurico Gaspar Dutra, utilizó sin mayores ceremonias los instrumentos intervencionistas del Estado. Además, con excepción del gobierno provisional de Café Filho, todos los gobiernos elaboraron extensos planes de desarrollo económico, el Plano Salte de Dutra y la Comissao Mixta CEPAL-BNDE de Vargas, que testimonian esta vocación de, si no intervenir, por lo menos dirigir la economía desde el sillón del Estado.

Teniendo en cuenta estos antecedentes de los gobiernos de Frondizi y Kubitschek, habría que añadir que ambos re- cibieron profundas influencias de las discusiones sobre el desarrollo económico que tenían lugar a finales de los años $50 \mathrm{y}$ en los que la CEPAL jugaba un papel preponderante.

El proyecto económico de Frondizi, que en gran medida mantenía las líneas establecidas durante gobierno militar a través del plan de Prebisch, partía de la premisa de que el desarrollo interno no podía basarse en las exportaciones agropecuarias porque éstas se encontraban atrapadas en el proceso de deterioro de los términos de intercambio, así como por su incapacidad de incidir en las condiciones impuestas por el comercio internacional. La financiación de la nueva etapa industrializadora, por lo tanto, debía producirse con la entrada masiva de capital extranjero y con un aumento de la tasa interna de ahorro.

Gradualmente, durante este gobierno, al mismo tiempo en que se disminuía la intervención del Estado sobre la economía se aumentaban los lazos de dependencia económica con el FMI y el capital internacional. Pero la creciente presión económica sobre los sectores asalariados intensificó las tensiones sociales, lo que llevó al gobierno a moderar su política salarial, monetaria y de gasto público. Como consecuencia se creó una situación de fricción con el FMI, lo que influyó también en el derrocamiento de Frondizi por los militares, en marzo de 1962.

Por su lado, la política económica del gobierno Kubitschek probablemente fue una de las aplicaciones más exitosas del principio de la planificación económica en América Latina.

A partir de discusiones internas del gobierno y basándose en las experiencias anteriores, éste formuló el conocido Plano de Metas, que fue un programa de evaluación y ejecución de propuestas para la economía brasileña, centradas en las áreas de la energía, transportes, alimentación, industria de base y educación. A través de la aplicación de esta política, el gobierno llevó a la práctica uno de los principios más discutidos por los economistas del desarrollo de la épo$\mathrm{ca}$, que es la idea de que algunos estímulos bien localizados en puntos clave de la economía naturalmente tendrían como consecuencia el desarrollo general del pais.

Además el gobierno adoptó una política en relación al capital externo consistente en que las inversiones internacionales se dirigieran sólo a los sectores en los que el país no tenía condiciones de un desarrollo autónomo, manteniendo en las manos del capital nacional, y principalmente del capital estatal, aquellos sectores suficientemente desarrollados por recursos internos.

Es interesante señalar que tanto en Argentina como en Brasil fue llevada al límite la idea de que el desarrollo económico conduciría inevitablemente a la modernidad pero, al mismo tiempo, en ambos países tanto el parlamento como la sociedad civil fueron excluidos, de una forma o de otra, de la aplicación y elaboración de los proyectos de cambio social.

En términos de los resultados económicos, la política llevada a cabo por Frondizi tuvo pocos frutos positivos. En todo el período la tasa de crecimiento del PNB se mantuvo estancada e, incluso, en algunos momentos fue negativa. Más allá de esto, la estrategia de autodisolución de la intervención estatal tuvo como consecuencia la disminución de la capacidad negociadora del sector público y de la capaci- 
dad del país para modificar su relación con los grandes centros económicos internacionales. Además, la estrategia de apertura irrestricta a los segmentos del capital internacional representados por el FMI aumentó la subordinación a las corporaciones transnacionales, a través también de nuevas formas de dependencia tecnológica.

Al contrario de lo que pasó en Argentina, en Brasil los resultados económicos del gobierno Kubitschek fueron un éxito. En términos del PNB, se pasó de una tasa de crecimiento de $2,9 \%$, en 1956 , al $9,4 \%$, en 1960 . Respecto a lo que se había propuesto en el Plano de Metas, en la mayoría de los objetivos se logró un gran rendimiento e incluso en el caso de la construcción de carreteras, se hizo más de lo que se había planteado. El gobierno fortaleció en gran medida su participación en sectores clave de la economía y a pesar de haber roto las relaciones con el FMI en junio de 1960, como consecuencia de un largo período de conflictos, esto constituyó un acicate para la búsqueda y establecimiento de nuevos y eficaces canales alternativos de captación de recursos externos.

\section{CONCLUSION}

Los casos de Frondizi y Kubitschek no dejan de ser paradigmáticos en la medida en que ambos parten de una situación política común, el régimen democrático y obtienen resultados económicos dispares. No obstante ello, ambos terminan enfrentándose a procesos de crisis politica que, antes o después, derivan en la ruptura del orden democrático.

En Argentina, el gobierno siguió los postulados que sostenían los grandes organismos internacionales, en especial el FMI, e intentó, con poco éxito, que estas directrices fomentasen el desarrollo del país. Sin duda esta experiencia invita a volver a preguntarse hasta qué punto al FMI realmente le interesó en la época (y le interesa hoy) fortalecer la economía de los países periféricos. Este es un problema que no deja de ser, a pesar de especulativo, muy importante: si realmente algún día podría existir interés en que todos los países del mundo se encuentren en una situación de paridad económica. Pero es algo que parece incompatible con el sistema capitalista, al menos tal como lo conocemos.

En el caso del gobierno Kubitschek, éste representa al mismo tiempo dos aspectos considerados contradictorios. Por un lado es un buen ejemplo de la capacidad de un gobierno democrático para estimular el desarrollo económico; pero, por otro lado, es también un buen ejemplo de un desarrollo económico que resultó en una crisis de la democracia. Probablemente la cuestión a discutir sobre este período, tanto en Brasil como en Argentina, se refiere a las consecuencias negativas de un desarrollo de la economía que no es acompañado por una política de estímulo de la ciudadanía y de desarrollo de las instituciones democráticas.

En este sentido, el desarrollo de las instituciones democráticas parece ser la gran asignatura pendiente de las estrategias de modernización elaboradas por los gobiernos de Frondizi y Kubitschek. Y ello, más que una materia de los libros de la historia pasada, está muy presente en las actuales propuestas de reforma económica en América Latina. El estudio de los casos analizados nos lleva a plantear que el precio que se paga por la subordinación de la politica democrática a los intereses del mercado económico es verdaderamente alto. Y sus consecuencias suelen ser muy graves para nuestras jóvenes o viejas pero siempre frágiles democracias. Es tarea también de los cientistas sociales contribuir a que ello no suceda así.

\section{BIBLIOGRAFIA}

Abreu, Marcelo de Paiva (org.) (1990): A orden do progresso: cem anos de politica econômica republicana. Rio de Janeiro, Campus.

Acuña, Marcelo Luis (1984): De Frondizi a Alfonsin: la tradición politica del radicalismo. (a) Vol.1 y (b)Vol.2. Buenos Aires, Centro Editor de América Latina.

Acuña, Carlos H.: "El análisis de la burguesía como actor político" en Realidad Económica, N. 128, 16 nov./31 dic. 1994. Buenos Aires.

Bielschowsky, Ricardo (1988): Pensamento Econômico Brasileiro: o ciclo ideológico do desenvolvimentismo. Río de Janeiro, IPEA/INPES.

Bledel, Rodolfo (1972): La economia argentina (19521972). Buenos Aires, Juárez Editor.

Bledel, Rodolfo (1969): Poder político y desarrollo económico. Buenos Aires, Juárez Editor.

Brailovsky, Antonio Elio (1982): Historia de las crisis argentinas. 1880-1982. Un sacrificio inútil. Buenos Aires, Editorial de Belgrano.

Brasil. (1958): Programa de Metas (v. I, II, III). Rio de Janeiro, Serviço de Documentaçao da Presidencia da República.

Cardoso, F.H. (1972): Estado y sociedad en América Latina. Buenos Aires, Ed. Nueva Visión.

Cardoso, F.H.: "The Entrepreneurial Elites of Latin America", en Studies in Comparative International Development, Vol.II, 10, 1966. St. Louis.

Cardoso, F.H. (1977): Ideologias de la burguesia industrial en sociedades dependientes (Argentina y Brasil). México, Siglo XXI.

Cardoso, F.H. y Faletto, E. (1978): Dependencia y desarrollo en América Latina. México, Siglo XXI.

CEPAL: "Principales características de la evolución histórica de la industria latinoamericana". En: Nolff, Max. (1974): Desarrollo Industrial Latinoamericano, México, FCE.

Conceição, Octavio Augusto Camargo: "Da crise do escravismo a crise do fordismo periférico no Brasil: uma proposta de periodização sob a ótica regulacionista". En: Conceição, O. A. C., Faria, Luis Augusto Estrella e Bello, Teresinha da Silva. (1990): Reflexoes sobre crise, regulação e capitalismo brasileiro. Porto Alegre, Fundaçap. de Economia e Estatistica.

Cueva, Agustín. (1977): El desarrollo del capitalismo en América Latina. México, Siglo XXI.

Díaz, Fanor (1977): Conversaciones con Rogelio Frigerio. Buenos Aires, Hachette.

Díaz Alejandro, C.F. (1974): Ensayos sobre la historia económica argentina. Buenos Aires, Amorrortu. 
Draibe, Sonia (1985): Rumos e Metamorfoses; un estudo sobre a constituição do Estado e as alternativas da industrialização no Brasil, 1930-1960. Rio de Janeiro, Paz e Terra.

Dutrénit Bielous, S. y Rodríguez Piña, J. (1989): "Argentina. Crisis y reorganización autoritaria de la sociedad en los años treinta: la ausencia de proyectos alternativos. En El impacto de la crisis del 29 en América Latina. México, Alianza Editorial Mexicana.

Ellsworth, P.T.: "The Terms of Trade between Primary Producing and Industrial Countries", en Interamerican Economic Affairs, vol. X, 1956.

Fajnzylber, Fernando (1983): La industrialización trunca de América Latina. Buenos Aires, CET.

Ferrer, Aldo (1981) (15a. edición): La economía argentina. Buenos Aires, FCE.

Ferrer, Aldo (1987): Crisis y alternativas de la politica económica argentina. Buenos Aires, FCE.

Fiori, José Luis. Democracia e Reformas: equívocos, obstáculos e disjuntivas. "Textos para discussao". UFRJ, Instituto de Economia Industrial, novembro/1991.

Flanders, M.J.: "Prebisch on protectionism. An evaluation", en Economic Journal, junio de 1964.

Frondizi, Arturo (1955): La lucha antiimperialista. Buenos Aires, Ediciones Debate.

Frondizi, Arturo (1956): Petróleo y política. Buenos Aires, Ediciones Debate.

Furtado, Celso (1969) (2a. edición): Subdesarrollo y estancamiento en América Latina. Buenos Aires, EUDEBA.

Furtado, Celso. (1972) (3a edição): Análise do modelo brasileiro. Rio de Janeiro, Civilização Brasileira.

Furtado, Celso (1978) (2a. edición): Prefacio a una nueva economía politica. México, Siglo XXI.

Furtado, Celso: "Transnacionalización y monetarismo", en Pensamiento Iberoamericano, No.1, enero-junio de 1982.

Furtado, Celso: "Dependencia en un mundo unificado", en Méndez, S. op.cit; pp.436/463.

Furtado, Celso (1985): La nueva dependencia. Deuda externa y monetarismo. Buenos Aires, CEAL.

Furtado, Celso (1991) (22a edición): La economia latinoamericana.Formación histórica y problemas contemporáneos. México, Siglo XXI.

Furtado, Celso: "O pensamento econômico latinoamericano. Entrevista. Novos Estudos, Cebrap, no41, marçc de 1995.

Furtado, Celso: "La invención del subdesarrollo", en Realidad Económica, No.133, 1 julio/15 agosto 1995. Buenos Aires.

Gourevitch, Peter (1993): Politicas estraiégicas en tiempos dificiles. Respuestas comparativas a las crisis económicas internacionales. México, FCE.

Gugliano, Alfredo Alejandro:"'Tristes Trópicos': algunas reflexiones sobre régimen político y modernización en Brasil" (Ameryka Lacinska, no 4, 1995. En prensa)

Hirschman, Albert O. (1981) (4a. edición): La estrategia del desarrollo económico. México, FCE.

Hirschman, Albert O: "Confesión de un disidente: revisión de la estrategia del desarrollo económico". En:
Hirschman, Albert O. (1989): Enfoques alternativos sobre la sociedad de mercado y otros ensayos más recientes. México, Fondo de Cultura Económica.

Instituto Cultural Uruguayo-Brasileño (1958): Juscelino Kubitschek. El hombre y su obra. Montevideo, ICUB.

Leff, Nathaniel (1977): Politica econômica e desenvolvimento no Brasil: 1947-1964. Sao Paulo, Perspectiva.

Lessa, Carlos (1983) (4⿳a ediçao): 15 años de política econômica. Sao Paulo, Brasiliense.

Luna, Félix (1993): Breve historia de los argentinos. Ed.Planeta/Espejo de la Argentina. Buenos Aires.

Maranhao, Ricardo. (1984) (3를. $)$ : O Governo Juscelino Kubitschek. Sao Paulo, Brasiliense.

Maravall, José María (1995): Los resultados de la democracia.Madrid, Alianza Editoriai.

Méndez V., Sofía (comp.) (1984): La crisis internacional y la América Latina. México, FCE.

Muñoz Goma, Oscar (1979): Desarrollo, distribución del ingreso y democratización. CIEPLAN. Estudios, No. 32.

O'Donnell, G., "Estado y Alianzas en la Argentina 1956-1976", en Desarrollo Económico, vol. 16, N.64, enero-marzo 1977. Buenos Aires.

Oliveira, Francisco.(1976) (2ª ed.): A Economia Brasileira: crítica à razao dualista. Seleções Cebrap, Sao Paulo, Brasiliense/Cebrap.

Orenstein, Luis e Sochaczewski, Antonio C.: "Democracia con desenvolvimento: 1956-1961". En Abreu (1990), op. cit.

Oszlak, Oscar (comp.)(1984): "Proceso", crisis y transición democrática/1 (a) y 2 (b). Buenos Aires, Centro Editor de América Latina.

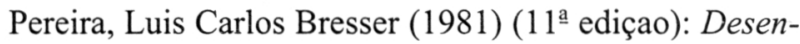
volvimento e crise no Brasil. Sao Paulo, Brasiliense.

Pereira, Luis Carlos Bresser: "Les entreprises multinationales et le sous-développment industrialisé", en Revue Tiers Monde, Tomo XIX, No.74, abril-junio de 1978.

Pinto, Aníbal: "La internacionalización de la economía mundial y la periferia", en Revista de la CEPAL, No.9, diciembre de 1979. Santiago de Chile.

Prebisch, Raúl: "Commercial policy in the underdeveloped countries", en American Economic Review, Papers and proceedings, mayo de 1959.

Prebisch, Raúl: "Estructura económica y crisis del sistema", en Revista de la CEPAL, No.6, segundo semestre de 1978. Santiago de Chile.

Prebisch, Raúl (1982): Contra el monetarismo. Buenos Aires, El Cid Editor.

Prebisch, Raúl: "Centro y periferia en el origen y la maduración de la crisis",en Pensamiento Iberoamericano, No.3, Revista de Economía Política del ICI, Madrid, enerojulio de 1983.

Rey, Esteban (1959): Frigerio y la traición de la burguesia industrial. Buenos Aires, Colección La Siringa, Peña Lillo Editor.

Rivera, Enrique (1958): Peronismo y Frondizismo. Buenos Aires, Ed. Patria Grande.

Rocca, Eduardo (1966): Argentina: los grupos dirigentes. Buenos Aires, Ed. Palestra. 
Rock, David. (1985): Argentina 1516-1987. Desde la colonización española hasta Raúl Alfonsin. Buenos Aires, Alianza.

Rodriguez, Octavio (1980): La teoria del subdesarrollo de la CEPAL. México, Siglo XXI.

Romero, Luis Alberto (1995): Breve Historia de Argentina. México, Fondo de Cultura Económica.

Rowland, Robert: "Classe operária e Estado de Compromisso". Revista Estudos (CEBRAP), nº8, 1974.

Sabato, Jorge F. (1988): La clase dominante en la Argentina moderna. Buenos Aires, CISEA/GEL.

Schvarzer, Jorge (1973): La industrialización argentina. Facultad de Ingeniería. Buenos Aires, UBA.

Schvarzer, Jorge: Estado y clase dominante en la Argentina moderna (1880 1990), en El Cielo por Asalto, n 5 , otoño/1993.

Selser, Gregorio (1965): Argentina a precio de Costo. El gobierno de Frondizi. Buenos Aires, Iguazú. Documentos/6.

Sikkink, Kathryn. "Las capacidades y la autonomía del Estado en Brasil y la Argentina. Un enfoque neoinstitucionalista". Desarrollo Económico, v.32, n¹28, enero-marzo/1993.
Singer, Paul y Lamounier, Bolivar: "Brasil: crecimiento con desigualdad" En: Nerfin, Marc. Compilador (1978): Hacia otro desarrollo. México, Siglo XXI.

Skidmore, Thomas (1982): Brasil: de Getúlio a Castelo. Rio de Janeiro, Paz e Terra.

Smulovitz, C. (1988): Oposición y gobierno: los años de Frondizi/1. CEAL. Buenos Aires, Siglo XXI.

Sunkel, O. y Tomassini, L.: "La crisis del sistema transnacional y el cambio en las relaciones internacionales de los países en desarrollo", en Méndez, S.(1984); pp. 53/92.

Suzigan, Wilson (1986): Indústria Brasileira - Origem e desenvolvimento. Sao Paulo, Brasiliense.

Tavares, María da Conceiçao (1964): “Auge y declinación del proceso de sustitución de importaciones en el Brasil". Boletín Económico de América Latina, Vol. IX, No.1. Marzo.

Tilly, Charles (1992): Coerción, Capital y los estados Europeos. Madrid, Alianza.

Torrado, Susana (1992): Estructura social de la Argentina: 1945-1983. Buenos Aires, Ediciones de La Flor.

Weffort, Francisco (1986) ( $3^{\mathrm{a}} \mathrm{ed}$.): O populismo na politica brasileira. Rio de Janeiro, Paz e Terra.

\section{RESUMEN}

López-Accotto y Gugliano se proponen, en estas páginas, hacer un ejercicio de comparación de las políticas económicas en Argentina y Brasil durante las gestiones de los presidentes Arturo Frondizi (1958-1962) y Juscelino Kubitscheck (1956-1961). Este estudio lo abordan desde una triple perspectiva: histórica, reconstruyendo los procesos a los que se hace referencia y procurando contextualizarlo históricamente; sociológico-política, centrándose en las estrategias económicas de cada gobierno; y, comparada, al tomar en consideración estos dos casos señalados.

ABSTRACT
López-Accotto and Gugliano tries, in this article, to compare economical politics in Argentina and
Brazil during the government of presidents Arturo Frondizi (1958-1962) and Juscelino Kubitscheck
(1956-1961). The authors faced this study with a triple perspective: historical, rebuilding these
proccesses and trying to contextualize them; sociological-political, focused on the economical strategy
of each government; and, comparative, taking into account these two cases.

